\title{
Thin-film thermoelectric generator based on polycrystalline SiGe formed by Ag-induced layer exchange
}

Cite as: Appl. Phys. Lett. 117, 162103 (2020); https://doi.org/10.1063/5.0021880

Submitted: 15 July 2020 • Accepted: 03 October 2020 • Published Online: 19 October 2020

M. Tsuji, (D) M. Murata, A. Yamamoto, et al.
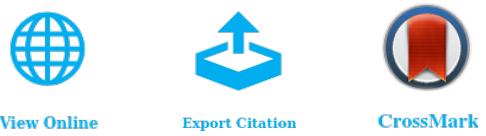

View Online

Export Citation

\section{ARTICLES YOU MAY BE INTERESTED IN}

Thickness-dependent thermoelectric properties of $\mathrm{Si}_{1-x} \mathrm{Ge}_{\mathbf{x}}$ films formed by Al-induced layer exchange

Journal of Applied Physics 129, 015303 (2021); https://doi.org/10.1063/5.0025099

Nanosecond carrier lifetimes in solution-processed enargite ( $\left.\mathrm{Cu}_{3} \mathrm{AsS}_{4}\right)$ thin films Applied Physics Letters 117, 162102 (2020); https://doi.org/10.1063/5.0023246

$\mathrm{Zn}$-induced layer exchange of $\mathrm{p}$ - and $\mathrm{n}$-type nanocrystalline SiGe layers for flexible thermoelectrics

Applied Physics Letters 116, 182105 (2020); https://doi.org/10.1063/5.0006958

田QBLOX

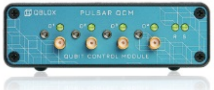

1 qubit
Shorten Setup Time Auto-Calibration More Qubits

\section{Fully-integrated} Quantum Control Stacks Ultrastable DC to $18.5 \mathrm{GHz}$ Synchronized $<<1$ ns Ultralow noise

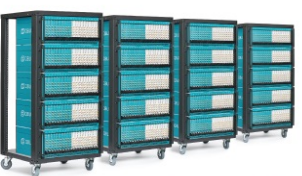

100s qubits

visit our website > 


\title{
Thin-film thermoelectric generator based on polycrystalline SiGe formed by Ag-induced layer exchange
}

Cite as: Appl. Phys. Lett. 117, 162103 (2020); doi: 10.1063/5.0021880

Submitted: 15 July 2020 - Accepted: 3 October 2020 .

Published Online: 19 October 2020

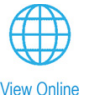

M. Tsuji, ${ }^{7}$ M. Murata, ${ }^{2, a)}$ (D) A. Yamamoto, ${ }^{2}$ T. Suemasu, ${ }^{1}$ (D) and K. Toko, ${ }^{1,3, a)}$ (D)

\author{
AFFILIATIONS \\ 'Institute of Applied Physics, University of Tsukuba, 1-1-1 Tennodai, Tsukuba, Ibaraki 305-8573, Japan \\ ${ }^{2}$ Research Institute for Energy Conservation, AIST, Tsukuba, Ibaraki 305-8569, Japan \\ ${ }^{3}$ PRESTO, Japan Science and Technology Agency, 4-1-8 Honcho, Kawaguchi, Saitama 332-0012, Japan
}

${ }^{a)}$ Authors to whom correspondence should be addressed: m.murata@aist.go.jp and toko@bk.tsukuba.ac.jp

\begin{abstract}
SiGe alloys are a promising material for highly reliable, human-friendly thin-film thermoelectric generators for micro-energy harvesting. However, it is difficult to obtain high performances at low thermal budgets in SiGe layers, especially in n-type materials. Ag-induced layer exchange enables the synthesis of $\mathrm{Si}_{1-x} \mathrm{Ge}_{x}(x: 0-0.3)$ layers at $50{ }^{\circ} \mathrm{C}$ and dynamically controls the Fermi level owing to the self-organizing manner of impurity doping during the layer exchange. Intrinsic, p-type (hole concentration $>10^{19} \mathrm{~cm}^{-3}$ ), and highly n-type (electron concentration $>10^{20} \mathrm{~cm}^{-3}$ ) SiGe layers are obtained using pure Ag, B-doped Ag, and As-doped Ag, respectively. Owing to the high carrier concentrations, the thermoelectric power factor at room temperature exhibits high values: $230 \mu \mathrm{W} \mathrm{m}^{-1} \mathrm{~K}^{-2}$ for the p-type and $1000 \mu \mathrm{W} \mathrm{m}^{-1} \mathrm{~K}^{-2}$ for the $\mathrm{n}$-type. The latter value is the highest reported power factor at room temperature for SiGe formed below $1000^{\circ} \mathrm{C}$. The dimensionless figure of merit is determined to be 0.19 from the power factor and the thermal conductivity of $1.6 \mathrm{~W} \mathrm{~m}^{-1} \mathrm{~K}^{-1}$. A thermoelectric generator fabricated with the low-temperature SiGe layers demonstrates a relatively large output for thin films $(50 \mathrm{~nm}): 1.4 \mathrm{nW}$ at room temperature with a temperature difference of $15^{\circ} \mathrm{C}$.
\end{abstract}

Published under license by AIP Publishing. https://doi.org/10.1063/5.0021880

Thin-film thermoelectric generators (TEGs) have been actively investigated in recent years for energy harvesting applications using micro energy. ${ }^{1}$ Because thin-film TEGs will be used in our daily lives, the material used to fabricate them should be nontoxic and reliable in addition to exhibiting high thermoelectric performances. $\mathrm{Si}_{1-x} \mathrm{Ge}_{x}$ ( $x$ : 0.1-0.3) alloy is a nontoxic, reliable, and well-tested thermoelectric material that has been used for decades in space applications because of its large Seebeck coefficient $S$ derived from $\mathrm{Si}$, high electrical conductivity $\sigma$ owing to Ge addition, and low thermal conductivity $\kappa$ owing to alloy phonon scattering. ${ }^{2,3}$ Bulk SiGe is fabricated using sintering methods; however, the process is complicated owing to the large difference in the melting point, which increases the production cost and complicates consumer applications. Conversely, the thin-film formation of SiGe can be achieved easily using various vapor deposition techniques. ${ }^{4-15}$ Furthermore, mature Si process technologies can be applied, including lithography and Fermi-level control, which are essential for thermoelectric applications. Therefore, SiGe is a promising candidate for thin-film TEGs.
Thin-film thermoelectric applications of SiGe have been studied using laser sintering, ${ }^{4}$ sputtering, ${ }^{5,6}$ chemical vapor deposition, ${ }^{7-11}$ electrophoretic deposition, ${ }^{12}$ solid-phase crystallization, ${ }^{13,14}$ and metal-induced crystallization. ${ }^{15}$ However, SiGe generally requires high temperatures for crystallization and dopant activation, which strictly limit its application. Metal-induced crystallization with layer exchange (LE) has overcome this problem. In addition to crystallizing $\mathrm{SiGe}$ at low temperatures, LE dopes and activates impurities into SiGe according to the solid solubility limit. ${ }^{16,17} \mathrm{We}$ achieved p-type SiGe with high power factors (PFs, $400 \mu \mathrm{W} \mathrm{m}{ }^{-1} \mathrm{~K}^{-2}$ ) at room temperature $(\mathrm{RT})$ via a low-temperature process $\left(<500{ }^{\circ} \mathrm{C}\right)$ using metal-induced LE with $\mathrm{Al}^{18}$ and $\mathrm{Zn}^{19}$ Generally, the lowtemperature synthesis of n-type SiGe is difficult because of the low solid-solubility and low activation rate of n-type dopants. ${ }^{20} \mathrm{We}$ achieved n-type SiGe (electron concentration: $10^{19} \mathrm{~cm}^{-3}$ ) at $350{ }^{\circ} \mathrm{C}$ using LE with As-doped $\mathrm{Zn} .^{21}$ However, the $P F$ remained extremely low $\left(<30 \mu \mathrm{W} \mathrm{m}{ }^{-1} \mathrm{~K}^{-2}\right)$ because $\mathrm{Zn}$ functions as a $\mathrm{p}$-type dopant for SiGe. 
Metal-induced LE using $\mathrm{Au}^{23,24}$ and $\mathrm{Ag}^{25,26}$ has been applied to $\mathrm{Si}$ and $\mathrm{Ge}$ for solar cell and transistor applications. An Au-induced LE allows Ge thin-film transistors to be fabricated on plastic substrates; ${ }^{27}$ furthermore, Ag-induced LE allows for the fabrication of both $\mathrm{p}$ - and n-type $\mathrm{Si}$ at $800^{\circ} \mathrm{C}$ using amorphous Si doped with $\mathrm{B}$ and $\mathrm{P} .{ }^{28}$ These achievements were possible because $\mathrm{Au}$ and $\mathrm{Ag}$ do not act as dopants and have low solid solubilities for both Si and Ge. ${ }^{29}$ The present study investigates Ag-induced LE for fabricating SiGe alloy thin films for thermoelectric applications. We fabricated both p- and n-type SiGe on glass at $500^{\circ} \mathrm{C}$ and demonstrated the TEG operation. The resulting ntype SiGe exhibited the highest recorded $P F\left(1000 \mu \mathrm{W} \mathrm{m}{ }^{-1} \mathrm{~K}^{-2}\right)$ at $\mathrm{RT}$ for SiGe formed at low temperatures $\left(<1000^{\circ} \mathrm{C}\right)$.

Figure 1(a) presents the schematics of the Ag-induced LE process. The Ag and amorphous (a-) $\mathrm{Si}_{1-x} \mathrm{Ge}_{x}(x: 0,0.15$, and 0.3 ) layers (50-nm-thick each) were sequentially prepared without breaking vacuum on $\mathrm{SiO}_{2}$ glass substrate at $\mathrm{RT}$ using radio frequency (RF) magnetron sputtering (base pressure $3.0 \times 10^{-4} \mathrm{~Pa}$ ) with Ar plasma. The RF power was set to $30 \mathrm{~W}$ for $\mathrm{Ag}$ and $50 \mathrm{~W}$ for $\mathrm{a}-\mathrm{Si}_{1-x} \mathrm{Ge}_{x}$. The samples were then annealed at $500-550^{\circ} \mathrm{C}(15 \mathrm{~h})$ in an $\mathrm{N}_{2}$ ambient furnace. The $\mathrm{Ag}$ layer was then etched away using an acidic solution $\left(\mathrm{H}_{3} \mathrm{PO}_{4}: \mathrm{HNO}_{3}: \mathrm{CH}_{3} \mathrm{COOH}: \mathrm{H}_{2} \mathrm{O}=16: 1: 1: 2\right)$ for $2 \mathrm{~min}$. To form $\mathrm{p}$ - and $\mathrm{n}$-type $\mathrm{SiGe}$ layers, the B-doped Ag layer was prepared using a B-doped Ag target (B concentration: 3\%-20\%), while the As-doped Ag layer (As concentration: $3 \%-20 \%$ ) was prepared using the co-sputtering of $\mathrm{Ag}$ and As targets. The purity of each material was $99.9 \%$. For each $\mathrm{SiGe}$ composition and conductivity type, the maximum $P F$ was obtained at

(a)

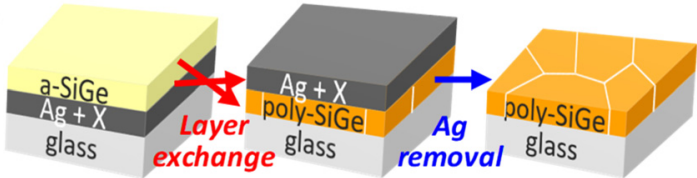

(b)
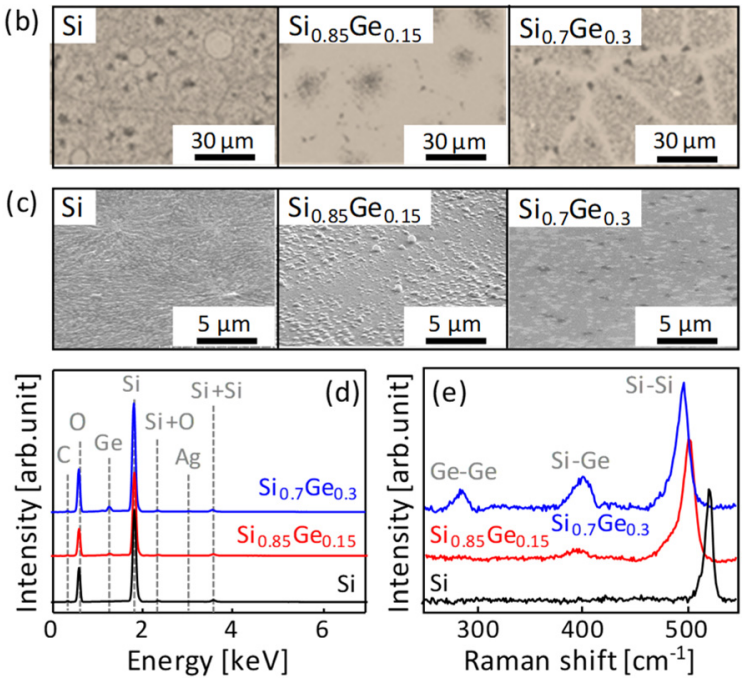

FIG. 1. (a) Schematic diagram of the sample preparation procedure. The metal layer can be Ag, B-doped Ag, or As-doped Ag. (b)-(e) Characteristics of the $\mathrm{Si}_{1-x} \mathrm{Ge}_{x}(x: 0,0.15$, and 0.3$)$ layers formed by $\mathrm{LE}$ at $500^{\circ} \mathrm{C}$ using pure $\mathrm{Ag}$, where Ag layers were removed: (b) Nomarski optical micrographs, (c) SEM images where the samples are $70^{\circ}$ tilted, (d) EDX spectra, and (e) Raman spectra. an annealing temperature of $500^{\circ} \mathrm{C}$ and an impurity amount of approximately $10 \%$. Therefore, we focus on these conditions for the experimental results below.

After the Ag etching, the layers remaining on the substrates were evaluated via Nomarski optical microscopy, scanning electron microscopy (SEM), energy dispersive $\mathrm{x}$-ray (EDX) spectroscopy, and Raman spectroscopy (wavelength $532 \mathrm{~nm}$ and spot size $5 \mu \mathrm{m}$ ). Figures 1 (b) and $1(\mathrm{c})$ show that, for each sample, a layer covers almost the entire substrate. According to the EDX spectra in Fig. 1(d), the Ag concentration in the layers is below the detection limit of EDX $(\sim 1 \%)$. Figure 1(e) shows the Raman peaks corresponding to $\mathrm{Si}-\mathrm{Si}, \mathrm{Si}-\mathrm{Ge}$, and $\mathrm{Ge}-\mathrm{Ge}$ vibration modes and indicates that crystalline $\mathrm{Si}_{1-x} \mathrm{Ge}_{x}$ layers are formed on the substrates by LE for all samples. The SiGe compositions, calculated from the Raman spectra using the equation proposed by Pezzoli et al., ${ }^{30}$ were consistent with those of the asprepared $\mathrm{a}-\mathrm{Si}_{1-x} \mathrm{Ge}_{x}$ layers determined by Rutherford backscattering spectrometry. These results indicate that the LE occurred between Ag and SiGe layers. Figures 1(b) and 1(c) also show that the surface morphology, especially the shape and distribution of the islands, ${ }^{16}$ differs depending on the sample. A similar behavior was observed in the $\mathrm{Zn}$ induced LE, ${ }^{21}$ which is likely due to the different nucleation rate of SiGe in metal depending on the Ge composition.

The crystallinity of the $\mathrm{Si}_{1-x} \mathrm{Ge}_{x}$ layers was evaluated using electron backscattering diffraction (EBSD) analysis. Figure 2 shows that crystal orientation differs slightly depending on both $x$ and the doping condition. The Si layer formed by the non-doped Ag exhibits a weak (111) orientation, whereas the orientation close to (100) appears due to the increase in $x$ and As addition. The grain size of $\mathrm{Si}$ is a few micrometers, which decreases slightly to submicrometers with increasing $x$. These grain sizes are smaller than those of the samples formed by Al-induced LE. ${ }^{18}$ The cross-plane $\kappa$ value of the As-doped $\mathrm{Si}_{0.85} \mathrm{Ge}_{0.15}$ sample was determined to be $1.6 \mathrm{~W} \mathrm{~m} \mathrm{~m}^{-1} \mathrm{~K}^{-1}$ by the PicoTherm PicoTR. The low $\kappa$ value is likely owing to phonon scattering by both

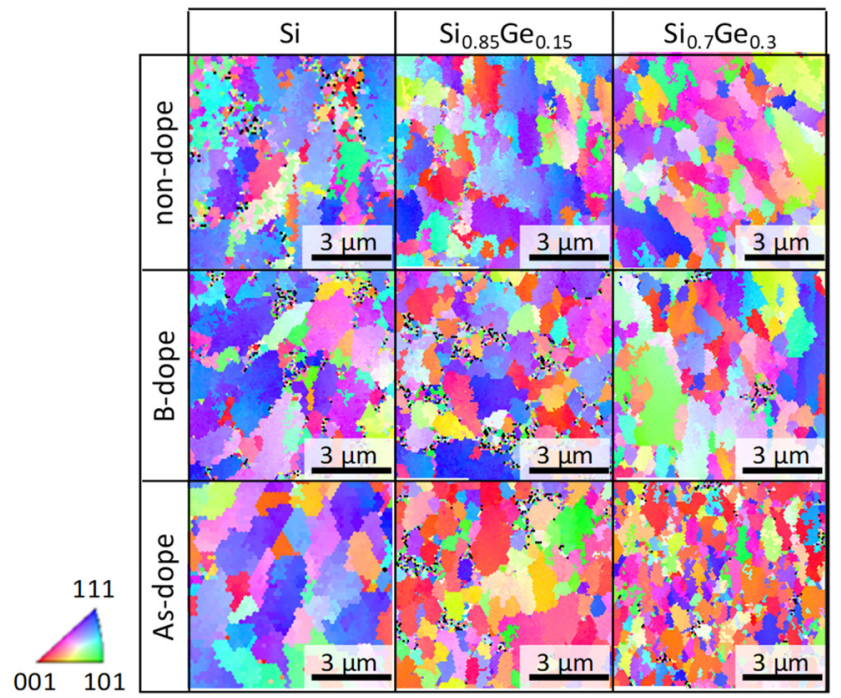

FIG. 2. Inverse pole figure images from EBSD analyses for $\mathrm{Si}_{1-x} \mathrm{Ge}_{x}(x=0,0.15$, and 0.3 ) formed by LE at $500{ }^{\circ} \mathrm{C}$ using non-doped, $10 \%$ B-doped, and $10 \%$ As-doped Ag. Colors indicate the crystal orientation according to the color key. 
high-density grain boundaries due to the small grains ${ }^{31}$ and the SiGe alloy structure. ${ }^{2}$

The carrier concentration of the samples was evaluated using Hall effect measurements based on the van der Pauw method. The samples formed by LE with pure Ag could not be measured because of the high resistivity, which suggests the intrinsic state. Conversely, the samples formed by LE with B- and As-doped Ag exhibited p- and $\mathrm{n}$-type conductions, respectively. These results indicate that $\mathrm{B}$ and $\mathrm{As}$ were doped and activated in $\mathrm{Si}_{1-x} \mathrm{Ge}_{x}$. Figure 3(a) shows that the hole concentration $p$ and electron concentration $n$ decrease with increasing $x$. The B-doped samples exhibit $p$ on the order of $10^{19} \mathrm{~cm}^{-3}$, whereas the As-doped samples exhibit $n$ on the order of $10^{20} \mathrm{~cm}^{-3}$. By extrapolating the curves showing the temperature dependence of the solid solubility of impurities in $\mathrm{Si}$, the solid solubility of $\mathrm{B}$ and $\mathrm{As}$ at $500^{\circ} \mathrm{C}$ is roughly estimated to be on the order of $10^{19}$ and $10^{20} \mathrm{~cm}^{-3}$, respectively. ${ }^{29}$ Therefore, the $p$ and $n$ behaviors likely reflect the solid solubility limits of $\mathrm{B}$ and $\mathrm{As}$ in $\mathrm{Si}_{1-x} \mathrm{Ge}_{x}$ at the current $\mathrm{LE}$ temperature, which is a feature of LE. ${ }^{16}$ Figure $3(\mathrm{~b})$ shows that $\sigma$ mainly reflects the carrier concentration. The As-doped $\mathrm{Si}_{1-x} \mathrm{Ge}_{x}(x \leq 0.15)$ shows a high $\sigma$ exceeding $500 \mathrm{~S} \mathrm{~cm}^{-1}$. This value is an order of magnitude higher than that of $\mathrm{n}$-type SiGe formed by $\mathrm{Zn}$-induced $\mathrm{LE} ;{ }^{21}$ therefore, excellent thermoelectric properties are expected.

Thermoelectric measurements were performed using an Advance-Riko ZEM system, where the sample was fixed to a ceramic stage using Ag paste. ${ }^{17}$ The $S$ value corresponding to the appropriate conduction type was obtained for each of the p-and n-type SiGe. Figure 3(c) shows that $|S|$ increases with the measurement temperature for all samples. This is a typical trend of degenerated semiconductors exhibiting metallic behavior and is attributed to the high $p$ and $n$. $^{2,3}$ Furthermore, $|S|$ depends on $x:|S|$ decreases with increasing $x$ for p-type samples; $|S|$ increases with increasing $x$ for n-type samples. This behavior is analogous to the basic physical properties of SiGe
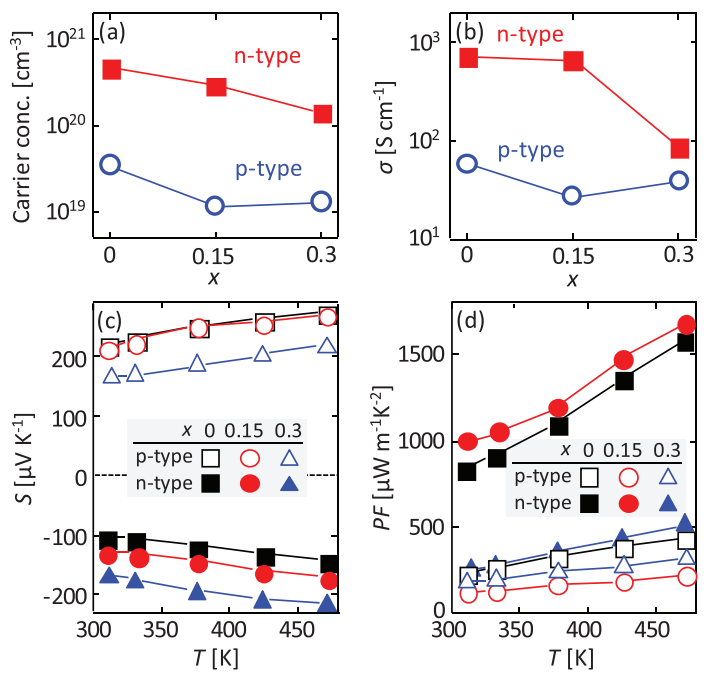

FIG. 3. Electrical and thermoelectric properties of $\mathrm{Si}_{1-x} \mathrm{Ge}_{x}(x=0,0.15$, and 0.3$)$ formed by LE at $500{ }^{\circ} \mathrm{C}$ using $10 \%$ B-doped $\mathrm{Ag}$ or $10 \%$ As-doped $\mathrm{Ag}$. (a) Hole concentration $p$ and electron concentration $n$; (b) electrical conductivity $\sigma$ as a function of $x$. (c) Seebeck coefficient $S$ and (d) power factor PF as a function of measurement temperature $T$. alloys and the behaviors of $p$ and $n$ [Fig. 3(a)]. ${ }^{2,3}$ Figure 3(d) shows that the $P F$ at RT reaches approximately $230 \mu \mathrm{W} \mathrm{m}{ }^{-1} \mathrm{~K}^{-2}$ for p-type $\mathrm{Si}$ and $1000 \mu \mathrm{W} \mathrm{m}{ }^{-1} \mathrm{~K}^{-2}$ for $\mathrm{n}$-type $\mathrm{Si}_{0.85} \mathrm{Ge}_{0.15}$. The difference in the $P F$ between the $\mathrm{p}$ - and n-types is attributed mainly to the difference in $\sigma$, which differs by an order of magnitude. The $P F$ of the n-type SiGe layer is the highest for SiGe thin films synthesized at $<1000^{\circ} \mathrm{C}$.

Figure 4(a) shows the setup to measure the output power of the in-plane $\pi$-type TEG fabricated using $\mathrm{p}$ - and $\mathrm{n}$-type $\mathrm{Si}_{0.85} \mathrm{Ge}_{0.15}$ with an $n-p-n$ series structure. B- and As-doped $\mathrm{Ag}$ and $\mathrm{a}-\mathrm{Si}_{0.85} \mathrm{Ge}_{0.15}$ (50-nm-thick each) were sequentially patterned on a $\mathrm{SiO}_{2}$ glass substrate using metal-mask evaporation, followed by annealing $\left(500{ }^{\circ} \mathrm{C}\right.$, $15 \mathrm{~h}$ ) for LE and Ag removal. Subsequently, Ag electrodes (500 nm thick) were prepared using the same sputtering system. A heater and heat sink were provided on each side to induce a temperature difference $(\Delta T=5,10$, and $15 \mathrm{~K})$ within the sample surface, where the sample stage was fixed at RT $(300 \mathrm{~K})$. We measured the current and voltage at a variable load resistance connected in series while changing its resistance. As shown in Fig. 4(b), by connecting the data points, we obtained ideal voltage-current lines and then power-current curves, indicating a TEG operation. The open-circuit voltage, short-circuit current, and output power increase with $\Delta T$. An open-circuit voltage of $5.0 \mathrm{mV}$ and a short-circuit current of $0.50 \mu \mathrm{A}$ are obtained at $\Delta T=10 \mathrm{~K}$. These values are almost consistent with the estimated values (open-circuit voltage: $4.7 \mathrm{mV}$; short-circuit current: $0.56 \mu \mathrm{A}$ ) from $|S|$ (n-type: $126 \mu \mathrm{V} \mathrm{K}^{-1}$; p-type: $214 \mu \mathrm{V} \mathrm{K}^{-1}$ ) and $\sigma$ (n-type: $625 \mathrm{Scm}^{-1}$; p-type: $26 \mathrm{~S} \mathrm{~cm}^{-1}$ ) of the $\mathrm{Si}_{0.85} \mathrm{Ge}_{0.15}$ layers. From the slope of the voltage-current lines, the internal resistance of the TEG is estimated to be approximately $10 \mathrm{k} \Omega$. This value is almost consistent with that calculated from $\sigma$ and the shapes of the current $\mathrm{p}$ - and n-type $\mathrm{Si}_{0.85} \mathrm{Ge}_{0.15}$ layers. The maximum output power reaches $1.4 \mathrm{nW}$ at $\Delta T=15 \mathrm{~K}$, which is still much smaller than the power $(>\mu \mathrm{W})$ required to operate micro-energy devices including sensors. There are two main limiting factors: (i) the high series resistance due to the low $\sigma$ of the p-type SiGe layer and (ii) the small volume due to the thin $\mathrm{SiGe}$ layers. The current output power is approximately an order of magnitude lower than that estimated only from n-type $\mathrm{Si}_{0.85} \mathrm{Ge}_{0.15}$.
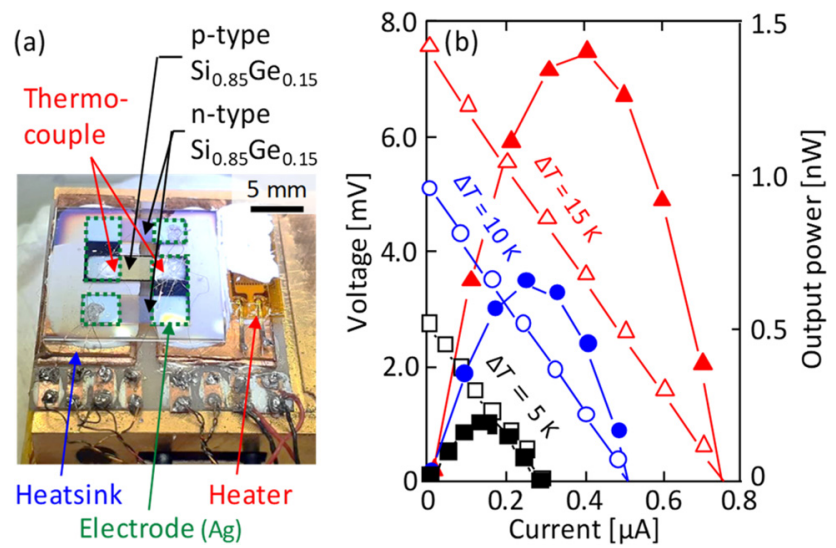

FIG. 4. Output power measurement of the TEG using p- and n-type $\mathrm{Si}_{0.85} \mathrm{Ge}_{0.15}$ formed on glass by $\mathrm{Ag}$-induced LE at $500^{\circ} \mathrm{C}$. (a) Photograph of the TEG and measurement setup. (b) Voltage-current lines and power-current curves of TEG obtained at constant temperature differences $\Delta T$ of $5 \mathrm{~K}$ (squares), $10 \mathrm{~K}$ (circles), and $15 \mathrm{~K}$ (triangles). The sample stage was kept at RT. 
This is because the total series resistance, i.e., the current, of the TEG is limited by p-type $\mathrm{Si}_{0.85} \mathrm{Ge}_{0.15}$ with a relatively low $\sigma$. The appropriate selection of the p-type layer with a high $\sigma$, such as that obtained by $\mathrm{Al}$-induced $\mathrm{LE},{ }^{18}$ is essential for not reducing the output power. Conversely, the total volume of SiGe in the current TEG is as small as $1.4 \times 10^{-6} \mathrm{~cm}^{-3}$ due to the thin film thickness $(50 \mathrm{~nm})$. Because the maximum output power of the TEG is proportional to the volume, thickening the film is the next issue for improving the power.

As shown in Fig. 5, SiGe generally requires high processing temperatures to obtain high $P F$ values at RT. This is mainly to activate the highly doped impurities in SiGe. For p-type SiGe, the LE technique enabled us to achieve both a high $P F$ and a low processing temperature $\left(\leq 500^{\circ} \mathrm{C}\right)$. This is because the $\mathrm{LE}$ metal catalysts ( $\mathrm{Al}$ and $\mathrm{Zn}$ ) acted as p-type dopants, which were then doped in a self-organizing manner during LE. ${ }^{18,21}$ Therefore, for p-type SiGe, the $P F$ obtained by LE using these metals exhibited higher values than those obtained by current LE using B-doped Ag. Generally, it is more difficult to achieve n-type SiGe than p-type SiGe at a low processing temperature because n-type dopants are difficult to activate in SiGe. The LE using As-doped Zn enabled us to form n-type $\mathrm{SiGe}$ at $\leq 350^{\circ} \mathrm{C}$; however, the $P F$ was low $\left(30 \mu \mathrm{W} \mathrm{m}{ }^{-1} \mathrm{~K}^{-2}\right){ }^{21}$ Conversely, the current LE using As-doped Ag yielded n-type SiGe with a high $P F\left(1000 \mu \mathrm{W} \mathrm{m} \mathrm{m}^{-1} \mathrm{~K}^{-2}\right)$ even in the $500{ }^{\circ} \mathrm{C}$ process. This occurred because $\mathrm{Ag}$ does not function as a dopant with respect to SiGe, and therefore, only As can be doped and activated in SiGe to the solid solution limit. From the $P F$ and $\kappa$ values, the dimensionless figure of merit of the $\mathrm{n}$-type $\mathrm{SiGe}$ is determined to be 0.19 at RT, which is relatively high for a thermoelectric thin film. Combining with p-type SiGe formed by Al- or $\mathrm{Zn}$-induced LE will yield excellent TEGs at low processing temperatures.

In conclusion, intrinsic SiGe alloy thin films were fabricated on glass using Ag-induced LE. The Fermi level of the resulting SiGe layers was dynamically controlled even at low processing temperature $\left(500^{\circ} \mathrm{C}\right)$ using self-organizing impurity doping during LE. B-doped Ag yielded p-type SiGe with $p$ values over $10^{19} \mathrm{~cm}^{-3}$, whereas As-doped Ag yielded n-type SiGe with $n$ values over $10^{20} \mathrm{~cm}^{-3}$. Owing to the high carrier concentrations, the $P F$ at RT indicated high values: $230 \mu \mathrm{W} \mathrm{m}{ }^{-1} \mathrm{~K}^{-2}$ for p-type Si and $1000 \mu \mathrm{W} \mathrm{m} \mathrm{m}^{-1} \mathrm{~K}^{-2}$ for n-type $\mathrm{Si}_{0.85} \mathrm{Ge}_{0.15}$. In particular, the n-type $P F$ was the highest

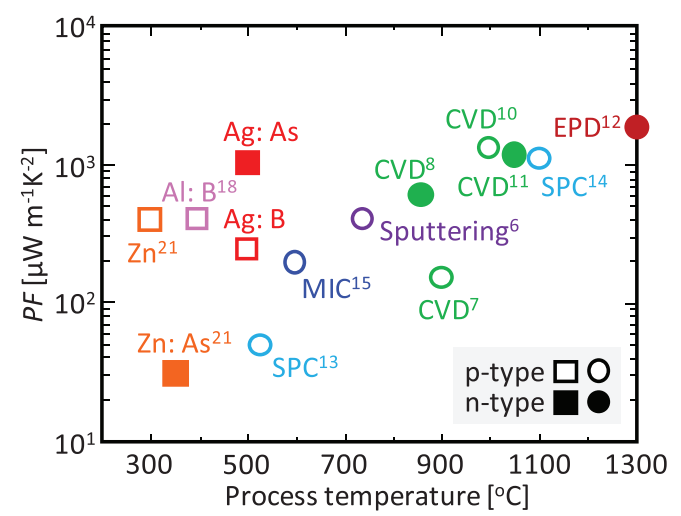

FIG. 5. Comparison of power factors $P F$ at around $R T$ and process temperatures of p- and n-type SiGe layers. Reference numbers are shown near each symbol. The metal type is shown for LE (squares), and the growth method is shown for the others (circles). recorded value for the SiGe layers at RT formed below $1000^{\circ} \mathrm{C}$. The TEG formed using the low-temperature SiGe layers output $1.4 \mathrm{nW}$ with $\Delta T=15 \mathrm{~K}$ at RT, despite the film thickness being only $50 \mathrm{~nm}$. Although the output power is still small, increasing the film thickness and selecting the appropriate metal catalyst for each p- and n-type SiGe will further improve the output power. Therefore, this study will be a milestone toward high-performance and reliable thin-film TEGs based on an environmentally friendly semiconductor.

This study was financially supported by the JST PRESTO (No. JPMJPR17R7) and the Thermal \& Electric Energy Technology Foundation. K.T. is grateful to Dr. M. Kurosawa (Nagoya University) for the helpful discussion regarding the power measurement, Professor T. Sakurai (University of Tsukuba) for the Hall effect measurements, and Ms. T. Tawara and Mr. K. Tanigawa (University of Tsukuba) for their help with experiments at the Nanotechnology Platform. EBSD measurements were conducted at the International Center for Young Scientists in NIMS.

\section{DATA AVAILABILITY}

The data that support the findings of this study are available from the corresponding author upon reasonable request.

\section{REFERENCES}

${ }^{1}$ I. Petsagkourakis, K. Tybrandt, X. Crispin, I. Ohkubo, N. Satoh, and T. Mori, Sci. Technol. Adv. Mater. 19, 836 (2018).

${ }^{2}$ J. P. Dismukes, L. Ekstrom, E. F. Steigmeier, I. Kudman, and D. S. Beers, J. Appl. Phys. 35, 2899 (1964).

${ }^{3}$ C. B. Vining, J. Appl. Phys. 69, 331 (1991).

${ }^{4}$ K. Xie, K. Mork, J. T. Held, K. A. Mkhoyan, U. Kortshagen, and M. C. Gupta, J. Appl. Phys. 123, 094301 (2018).

${ }^{5}$ K. Tajima, W. Shin, M. Nishibori, N. Murayama, T. Itoh, N. Izu, and I. Matsubara, Key Eng. Mater. 320, 99 (2006).

${ }^{6}$ J. A. Perez-Taborda, M. Muñoz Rojo, J. Maiz, N. Neophytou, and M. MartinGonzalez, Sci. Rep. 6, 32778 (2016).

${ }^{7}$ M. Takashiri, T. Borca-Tasciuc, A. Jacquot, K. Miyazaki, and G. Chen, J. Appl. Phys. 100, 054315 (2006).

${ }^{8}$ Z. Wang, P. Fiorini, V. Leonov, and C. Hoof, J. Micromech. Microeng. 19, 094011 (2009).

${ }^{9}$ R. Cheaito, J. C. Duda, T. E. Beechem, K. Hattar, J. F. Ihlefeld, D. L. Medlin, M. A. Rodriguez, M. J. Campion, E. S. Piekos, and P. E. Hopkins, Phys. Rev. Lett. 109, 195901 (2012).

${ }^{10}$ J. Lu, R. Guo, W. Dai, and B. Huang, Nanoscale 7, 7331 (2015).

${ }^{11}$ J. Lu, R. Guo, and B. Huang, Appl. Phys. Lett. 108, 141903 (2016).

${ }^{12}$ A. Nozariasbmarz, A. Tahmasbi Rad, Z. Zamanipour, J. S. Krasinski, L. Tayebi, and D. Vashaee, Scr. Mater. 69, 549 (2013).

${ }^{13}$ H. Takiguchi, M. Aono, and Y. Okamoto, Jpn. J. Appl. Phys., Part 1 50, 041301 (2011).

${ }^{14}$ Y. Peng, L. Miao, J. Gao, C. Liu, M. Kurosawa, O. Nakatsuka, and S. Zaima, Sci. Rep. 9, 14342 (2019).

${ }^{15}$ M. Lindorf, H. Rohrmann, G. Span, S. Raoux, J. Jordan-Sweet, and M. Albrecht, J. Appl. Phys. 120, 205304 (2016).

${ }^{16}$ K. Toko and T. Suemasu, J. Phys. D: Appl. Phys. 53, 373002 (2020).

${ }^{17}$ K. Kusano, A. Yamamoto, M. Nakata, T. Suemasu, and K. Toko, ACS Appl. Energy Mater. 1, 5280 (2018).

${ }^{18} \mathrm{M}$. Tsuji, T. Imajo, N. Saitoh, N. Yoshizawa, T. Suemasu, and K. Toko, J. Phys. D: Appl. Phys. 53, 075105 (2020).

${ }^{19}$ K. Kusano, M. Tsuji, T. Suemasu, and K. Toko, Appl. Phys. Express 12, 055501 (2019).

${ }^{20}$ M. Koike, Y. Kamata, T. Ino, D. Hagishima, K. Tatsumura, M. Koyama, and A. Nishiyama, J. Appl. Phys. 104, 023523 (2008). 
${ }^{21}$ M. Tsuji, K. Kusano, T. Suemasu, and K. Toko, Appl. Phys. Lett. 116, 182105 (2020).

${ }^{22}$ S. M. Sze and J. C. Irvin, Solid. State. Electron. 11, 599 (1968).

${ }^{23}$ J.-H. Park, M. Kurosawa, N. Kawabata, M. Miyao, and T. Sadoh, Electrochem. Solid-State Lett. 14, H232 (2011).

${ }^{24}$ J.-H. Park, K. Kasahara, K. Hamaya, M. Miyao, and T. Sadoh, Appl. Phys. Lett. 104, 252110 (2014).

${ }^{25}$ M. Scholz, M. Gjukic, and M. Stutzmann, Appl. Phys. Lett. 94, 012108 (2009).

${ }^{26}$ R. Yoshimine, K. Toko, N. Saitoh, N. Yoshizawa, and T. Suemasu, J. Appl. Phys. 122, 215305 (2017).
${ }^{27}$ H. Higashi, M. Nakano, K. Kudo, Y. Fujita, S. Yamada, T. Kanashima, I. Tsunoda, H. Nakashima, and K. Hamaya, Appl. Phys. Lett. 111, 222105 (2017).

${ }^{28}$ T. Antesberger, T. a Wassner, C. Jaeger, M. Algasinger, M. Kashani, M. Scholz, S. Matich, and M. Stutzmann, Appl. Phys. Lett. 102, 212102 (2013).

${ }^{29}$ F. A. Trumbore, Bell Syst. Tech. J. 39, 205 (1960).

${ }^{30}$ F. Pezzoli, L. Martinelli, E. Grilli, M. Guzzi, S. Sanguinetti, M. Bollani, H. D. Chrastina, G. Isella, H. von Känel, E. Wintersberger, J. Stangl, and G. Bauer, Mater. Sci. Eng., B 124-125, 127 (2005).

${ }^{31}$ Y. Nakamura, M. Isogawa, T. Ueda, S. Yamasaka, H. Matsui, J. Kikkawa, S. Ikeuchi, T. Oyake, T. Hori, J. Shiomi, and A. Sakai, Nano Energy 12, 845 (2015). 